\title{
Circulating IGF1 regulates hippocampal IGF1 levels and brain gene expression during adolescence
}

\author{
Han Yan, Matthew Mitschelen, Georgina V Bixler ${ }^{1}$, Robert M Brucklacher ${ }^{1}$, Julie A Farley, Song Han, \\ Willard M Freeman ${ }^{1}$ and William E Sonntag
}

Reynolds Oklahoma Center on Aging, Donald W. Reynolds Department of Geriatric Medicine, University of Oklahoma Health Sciences Center, 975 NE 10 th ST BRC 1305, Oklahoma City, Oklahoma 73104, USA

${ }^{1}$ Genome Sciences Facility, Penn State College of Medicine, Hershey, Pennsylvania 17033, USA

(Correspondence should be addressed to W E Sonntag; Email: william-sonntag@ouhsc.edu)

\begin{abstract}
GH and its anabolic mediator, IGF1, are important not only in somatic growth but also in the regulation of brain function. Even though GH treatment has been used clinically to improve body composition and exercise capacity in adults, its influence on central nervous system function has only recently been recognized. This is also the case for children with childhoodonset GH deficiency (GHD) where GH has been used to stimulate bone growth and enhance final adult height. Circulating IGF1 is transported across the blood-brain barrier and IGF1 and its receptors are also synthesized in the brain by neurons and glial and endothelial cells. Nevertheless, the relationship between circulating IGF1 and brain IGF1 remains unclear. This study, using a GH-deficient dwarf rat model and peripheral GH replacement, investigated the effects of circulating
\end{abstract}

IGF1 during adolescence on IGF1 levels in the brain. Our results demonstrated that hippocampal IGF1 protein concentrations during adolescence are highly regulated by circulating IGF1, which were reduced by GHD and restored by systematic GH replacement. Importantly, IGF1 levels in the cerebrospinal fluid were decreased by GHD but not restored by GH replacement. Furthermore, analysis of gene expression using microarrays and RT-PCR indicated that circulating IGF1 levels did not modify the transcription of Igf1 or its receptor in the hippocampus but did regulate genes that are involved in microvascular structure and function, brain development, and synaptic plasticity, which potentially support brain structures involved in cognitive function during this important developmental period.

Journal of Endocrinology (2011) 211, 27-37

\section{Introduction}

$\mathrm{GH}$ and its downstream mediator, insulin-like growth factor 1 (IGF1), are important for mammalian growth and development. GH and IGF1 levels are relatively low during early childhood, increase to high levels during adolescence and then progressively decrease with age (Smith et al. 1989). There are many causes for impairments in GH and IGF1 secretion during adolescence including, but not limited to, traumatic brain injury, malformations of the hypothalamic/ pituitary gland, neoplasm within the hypothalamus or pituitary, and cranial radiation (Krysiak et al. 2007). In addition to the fact that $\mathrm{GH}$ replacement therapy is used to increase bone growth (to increase final height), and improve body composition, lipids and exercise capacity in GH-deficient individuals (Carroll et al. 1998, Krysiak et al. 2007), the importance of GH therapy for function of the central nervous system (CNS) has also been recognized since the mid-1990s (Johansson et al. 1995, Nyberg \& Burman 1996, Burman \& Deijen 1998) and additional information regarding this relationship has recently become more apparent
(Ross 2005, Aleman \& Torres-Aleman 2009, de Bie et al. 2010). In adults, GH deficiency (GHD) is associated with progressive cognitive dysfunction (Deijen et al. 1996, Lijffijt et al. 2003, van Dam et al. 2005, Koltowska-Haggstrom et al. 2006) that can be reversed by GH treatment (Sartorio et al. 1995, Deijen et al. 1998, Golgeli et al. 2004, Oertel et al. 2004, Arwert et al. 2006). Nevertheless, the importance of GH replacement for CNS function in childhood-onset GHD (CO-GHD) has received less attention even though there are several reports of improved cognitive function after $\mathrm{GH}$ treatment (Hokken-Koelega et al. 2005, Ross 2005, Myers et al. 2007). Similarly, in rodents, cognitive impairment has been reported to be associated with the age-related decline in GH and IGF1 (Svensson et al. 2006) and can be restored by GH and/or IGF1 treatment (Markowska et al. 1998, Ramsey et al. 2004). In a dwarf rat model with reduced levels of serum GH and IGF1 beginning before adolescence, early intervention with $\mathrm{GH}$ for 10 weeks starting around puberty was reported to ameliorate age-related pathology in later life and increase lifespan (Sonntag et al. 2005). Importantly, restoration of $\mathrm{GH}$ for this brief period led to improved cognitive 
performance in adulthood and midlife (Nieves-Martinez et al. 2010). To date, the specific mechanisms for the improvements in cognitive function in response to GH/IGF1 replacement have not been clearly established.

Although circulating IGF1 is mainly produced and released from the liver, GH and IGF1 are also synthesized in numerous tissues including neurons, glia, and vascular cells within the brain providing further evidence that these hormones have an important role in brain function (Bondy et al. 1992, Donahue et al. 2006). IGF1 protein levels in brain represent contributions from both the CNS and the circulation since circulating IGF1 has been shown to cross the blood-brain barrier (Armstrong et al. 2000, Carro et al. 2000, Pan \& Kastin 2000). In addition, it has recently been demonstrated that neuronal activity increases IGF1 uptake through the bloodbrain barrier (Nishijima et al. 2010). Nevertheless, in a model of adult-onset GHD, a 50\% reduction in circulating IGF1 was reported to have no effect on IGF1 protein levels in the brain (Adams et al. 2009). These results challenged the current dogma related to the contribution of circulating IGF1 to IGF1 levels in the brain and led us to investigate the regulation of brain IGF1 levels during adolescence, an important point during the lifespan when circulating GH and IGF1 are at peak levels. We hypothesized that brain IGF1 protein expression is highly regulated by uptake of circulating IGF1 across the blood-brain barrier and/or by paracrine IGF1 gene expression in brain. To date, the effects of alterations in peripheral GH/IGF1 on regulation of neuronal/glial IGF1 gene expression and protein levels have not been assessed during adolescence.

The goal of this study was to investigate the regulation of brain IGF1 levels during adolescence, and explore the effects of GH and IGF1 deficiency and replacement on brain gene expression that we expect contribute to long-term modifications in brain development, function, learning and memory. To this end, we used a unique model of GH/IGF1 deficiency (the Lewis dwarf $(d w / d w)$ rat), which demonstrates reduced pituitary $\mathrm{GH}$ and decreased plasma IGF1 levels without changes in other anterior pituitary hormones (Charlton et al. 1988, Carter et al. 2002). Our results provide compelling evidence that brain IGF1 levels are dependent on circulating $\mathrm{GH}$ and IGF1 levels during adolescence and that these hormones regulate gene expression associated with vascular development and learning and memory.

\section{Materials and Methods}

\section{Animal model}

Homozygous dwarf $(d w / d w)$ and wild-type Lewis rats were purchased from Harlan Laboratories (Indianapolis, IN, USA). Homozygous dwarf males were bred with wild-type Lewis females to produce heterozygous (HZ) offspring of normal size; subsequently $\mathrm{HZ}$ females were bred with $d w / d w$ males to produce both $d w / d w$ and $\mathrm{HZ}$ littermates for experimental use. All experimental animals were housed 3-4 per cage in a pathogen-free rodent barrier facility at the University of Oklahoma Health Sciences Center (OUHSC) on a $12 \mathrm{~h}$ light: $12 \mathrm{~h}$ darkness cycle with food and water made available ad libitum. All animal protocols were in accordance with Guidelines for the Care and Use of Experimental Animals and approved by the Institutional Animal Care and Use Committee of OUHSC.

Experimental animals were weaned at 21 days of age and body weights were recorded twice weekly. At postnatal days 32-33, $\sim 0.2 \mathrm{ml}$ of blood was taken from the tail vein under isoflurane inhalation anesthesia. Serum was collected after centrifugation $\left(2500 \mathrm{~g}, 20 \mathrm{~min}, 4{ }^{\circ} \mathrm{C}\right)$ and IGF1 levels were determined by ELISA (see methodology below). Since the specific genetic mutation(s) in the dwarf rat has not been reported, $d w / d w$ rats were identified based on the three criteria compared with HZ animals: 1) reduced body weight, 2) impaired rates of growth, and 3) reduced serum IGF1 levels.

Dwarf males were randomly assigned to experimental and control groups and accordingly received s.c. injection of either $300 \mu \mathrm{g}$ recombinant porcine GH (Alpharma, distributed by OzBioPharm, Knoxfield, VIC, Australia) $(d w / d w+\mathrm{GH}$ group) or vehicle $(d w / d w+$ saline group), twice per day from postnatal day 35. The dose of GH was adapted from previous studies in our laboratory and is based on the ability to increase serum IGF1 and body weight to levels comparable to HZ animals (Sonntag et al. 2005). Male $\mathrm{HZ}$ littermates received the same volume of saline injection and served as an additional control (HZ group). To assess the short-term effects of $\mathrm{GH}$ replacement, rats were injected for 7 days; another cohort was injected for 30 days to test the intermediate effects of $\mathrm{GH}$ replacement. In the 7-day experiment, body weights were monitored daily and in the 30-day study, animals were weighed daily during the first week of injection to validate the response to $\mathrm{GH}$ replacement, and thereafter weighed twice weekly. One day before injection was initiated and at the end of study, whole body lean and fat mass was measured using a Bruker LF90 Minispec NMR analyzer (Bruker, Billerica, MA, USA). For both the 7- and 30-day studies, two cohorts were used. One cohort was anesthetized with a mixture of ketamine and xylazine (80 and $12 \mathrm{mg} / \mathrm{kg}$, respectively) at the end of the study to collect serum, cerebrospinal fluid (CSF) and hippocampal tissue for IGF1 analysis; the other cohort was decapitated without anesthesia to collect hippocampal tissue for microarray analysis and real-time PCR assay.

\section{CSF, serum, and hippocampal tissue collection}

CSF was collected by cisternal puncture (Waynforth \& Flecknell 1992) under anesthesia. Out of 89 rats, 40-100 $\mu 1$ CSF could be collected from $80 \%$ of the animals, of which $\sim 60 \%$ was visibly clear. Thereafter, cardiac blood was drawn from the left ventricle of the heart, serum was collected and 
stored at $-80^{\circ} \mathrm{C}$. Subsequently, animals were transcardially perfused with $0 \cdot 1 \mathrm{M}$ PBS ( $\mathrm{pH} 7 \cdot 4)$ containing $5 \mathrm{mM}$ dextrose and 5200 units/ heparin to remove blood from the brain. The brain was removed and the hippocampus was dissected on ice, weighed, quickly frozen in liquid nitrogen and stored at $-80^{\circ} \mathrm{C}$. Animals with blood remaining in the brain due to incomplete perfusion were excluded from further analysis, leading to uneven sample numbers per group for the hippocampal IGF1 protein measurement.

To validate the quality of collected CSF, absorption of hemoglobin ( $\mathrm{Hb}$ ) at $416 \mathrm{~nm}$ (Morselt et al. 1973) was used as a quantitative measurement of blood contamination. Based on preliminary data, IGF1 levels in CSF are $\sim 1 \%$ of the IGF1 levels in serum. Assuming 5\% as acceptable variance for IGF1 concentration, we calculated that contamination of CSF with blood needed to be $<0.05 \%$ (1:2000). Heparinized blood from Lewis rats was serially diluted in PBS (1:200 through 1:8000) to create a standard curve of $\mathrm{Hb}$ absorption. Standards and visibly clear CSF samples were vortexed, and absorption at $416 \mathrm{~nm}(1.5 \mu \mathrm{l}$ of each sample) was read using a NanoDrop ND-1000 Spectrophotometer (Thermo Scientific, Wilmington, DE, USA). CSF samples with $\mathrm{A}_{416}$ values greater than the $\mathrm{A}_{416}$ of 1:2000 diluted blood were defined as contaminated and therefore excluded from the data analysis.

\section{Extraction of IGF1 from hippocampal tissue}

The extraction method used in this study was adapted from the protocol of Adams et al. (2009) originally derived from D'Ercole et al. (1984), which demonstrated optimal recovery and consistency for IGF1 extraction from tissue. In brief, frozen left hippocampi (in sets of 8-12, including all three treatment groups) were placed into $2 \mathrm{ml}$ Wheaton glass tissue grinders (Wheaton, Millville, NJ, USA) containing $1 \mathrm{M}$ ice-cold sodium acetate homogenization buffer ( $\mathrm{pH} 3 \cdot 6,15 \mu \mathrm{l} / \mathrm{mg}$ tissue) and homogenized on ice to uniform appearance after equivalent strokes. Aliquots of $250 \mu \mathrm{l}$ from each homogenate were incubated at $4{ }^{\circ} \mathrm{C}$ with shaking at 1400 r.p.m. for $2 \mathrm{~h}$. After centrifuging at $3000 \mathrm{~g}\left(4^{\circ} \mathrm{C}\right)$ for $10 \mathrm{~min}$, supernatants were collected and stored for $1-2$ days at $-80^{\circ} \mathrm{C}$. Frozen supernatants were dried at $30^{\circ} \mathrm{C}$ for $2.5 \mathrm{~h}$ in a Vacufuge concentrator (Eppendorf, Hamburg, Germany). Dried extracts were capped and stored at $-80^{\circ} \mathrm{C}$ until IGF1 measurement within 1 week. Dried hippocampal extracts were brought to room temperature, reconstituted with $250 \mu 10 \cdot 1$ M HEPES buffer $(\mathrm{pH} 7 \cdot 8)$, dissolved by pipetting and gently vortexed, and centrifuged at room temperature $(3000 \boldsymbol{g}, 10 \mathrm{~min})$. Supernatants were used for IGF1 immunoassay.

\section{IGF1 measurement in CSF, serum, and hippocampal tissue}

IGF1 levels were determined by ELISA using the R\&D systems Quantikine mouse IGF1 immunoassay kit (Minneapolis, MN, USA), which demonstrates high cross-reactivity with rat IGF1. CSF samples were diluted in kit calibrator diluent at 1:10; serum samples were diluted serially in kit calibrator diluent at 1:2000. Results are presented as ng IGF1/ml in undiluted CSF or serum respectively. Hippocampal tissue extracts were measured without dilution, and results are shown as pg IGF1/mg hippocampal tissue.

\section{Illumina microarray and real-time PCR analysis}

To assess gene expression after GH replacement, 24 animals were used in total, with four animals in each group for the 7- and 30-day studies respectively. Animals were rapidly decapitated without anesthesia, the brains were removed quickly and hippocampi were dissected on ice, frozen in liquid nitrogen and stored at $-80^{\circ} \mathrm{C}$ until RNA isolation.

Left hippocampi were subjected to Illumina microarray analysis performed at the Penn State College of Medicine Genome Sciences Facility according to standard procedures as described previously (Freeman et al. 2009). Total RNA was extracted using Tri-Reagent (Molecular Research Center, Cincinnati, OH, USA) and purified using an RNeasy Mini Kit (Qiagen, Valencia, CA, USA). RNA quantity and quality were determined using a NanoDrop ND-1000 Spectrophotometer (Thermo Scientific) and RNA 6000 Nano LabChip with an Agilent 2100 Bioanalyzer (Agilent Technologies, Palo Alto, CA, USA). All RNA used had RNA integrity (RIN) values $>8$.

RNA samples ( $n=4 /$ group) were labeled according to the Illumina TotalPrep RNA Amplification kit (Life Technologies, Carlsbad, CA, USA) standard procedures. RNA (5 $\mathrm{ng}$ ) was reverse transcribed to synthesize first-strand cDNA by incubating samples at $42^{\circ} \mathrm{C}$ for $2 \mathrm{~h}$ with $\mathrm{T} 7$ Oligo(dT) primer, $10 \times$ first-strand buffer, dNTPs, RNase inhibitor, and ArrayScript. Second-strand cDNA was synthesized with $10 \times$ second-strand buffer, dNTPs, DNA polymerase, and $\mathrm{RNase} \mathrm{H}$ at $16{ }^{\circ} \mathrm{C}$ for $2 \mathrm{~h}$. cDNA was purified according to standard procedures. cDNA was eluted in $\sim 17.5 \mu \mathrm{l} 55^{\circ} \mathrm{C}$ nuclease-free water and was in vitro transcribed to synthesize cRNA using MEGAscript (Ambion, Austin, TX, USA) kit. Samples were incubated with T7 $10 \times$ reaction buffer, T7 Enzyme mix and BiotinNTP mix at $37^{\circ} \mathrm{C}$ for $14 \mathrm{~h}$. cRNA was purified according to instructions. cRNA yield was measured using a NanoDrop ND-1000 (Thermo Scientific).

Purified cRNA (750 ng) was prepared for hybridization according to instructions for hybridizing to Illumina RatRef12 Expression BeadChips. Chips were incubated in a hybridization oven for $20 \mathrm{~h}$ at $58^{\circ} \mathrm{C}$ at a rocker speed of 5 . After $20 \mathrm{~h}$, chips were disassembled, washed and StreptavidinCy3 stained according to Illumina standard procedures. Chips were dried by centrifugation at $275 \mathrm{~g}$ for $4 \mathrm{~min}$ and subsequently scanned using a BeadArray Reader. Images were imported into GenomeStudio software v2010.1 (Illumina, Inc., San Diego, CA, USA). Initial quality control (positive and negative controls), background subtraction, and intra-array normalization were performed.

Selected targets from the gene expression data were confirmed by real-time PCR. Right hippocampi from the 
Table 1 List of genes and assays for real-time PCR

\section{Gene ID}

\section{Gene names}

Insulin-like growth factor 1 Igf1

Insulin-like growth factor 1 Igf1R receptor

Arachidonate 15-lipoxy- Alox15 genase

$\alpha$-Globin

$\beta$-Globin

MGC72973

Hemoglobin $\alpha$, adult chain $2 \mathrm{Hba}-\mathrm{a} 2$

Calcium/calmodulin-

dependent protein

kinase kinase $2, \beta$

Pleiotrophin
$\mathrm{ABI}$ assay numbers

Rn00710306_m1

Rn01477918_m1

Rn00696151_m1

Rn01463755_g1

Rn02396921_g1

Rn01789798_s1

Rn00580133_m1

Ptn analysis (Allison et al. 2006) and previously published methods (Brucklacher et al. 2008). Lastly, probe sequences on the array were searched against current rat genome sequences to eliminate any probes for sequences removed from the NCBI database.

For the real-time PCR data, relative quantification based upon $2^{-\Delta \Delta C_{\mathrm{t}}}$ was analyzed with $\mathrm{RQ}$ manager 1.2 software (Applied Biosystems) using the geometric mean of $18 \mathrm{~s}$ and $\beta$-actin as endogenous controls.

SigmaStat 3.5 software (SYSTAT Software, Inc., Chicago, IL, USA) was used for statistical analysis. Two-way repeated measures ANOVA (with group and time as fixed factors) was used for the body weight and lean/fat mass analysis; IGF1 levels in CSF, serum, and hippocampal tissue, as well as real-time PCR results were analyzed by one-way ANOVA with a post hoc Student-Newman-Keuls test. Data are presented as mean \pm s.E.M. Differences were considered statistically significant if $P<0 \cdot 05$.

decapitated animals were subjected to total RNA isolation as described earlier. All RNA used had RIN values $>9 \cdot 2$. Reverse transcription was carried out to synthesize cDNA using a High Capacity cDNA Reverse Transcription Kit (Applied Biosystems, Foster City, CA, USA) according to the manufacturer's instructions. The $20 \mu \mathrm{l}$ reaction included $0.9 \mu \mathrm{g}$ RNA as the template, with both $500 \mathrm{ng}$ Oligo $\mathrm{dT}_{(12-18)}$ and $2 \mu \mathrm{l} 10 \times$ random primers for initiating the synthesis, together with $100 \mathrm{mM}$ dNTPs mix, $10 \times \mathrm{RT}$ buffer, 20U RNase inhibitor, and 50U MultiScribe reverse transcriptase. The reaction was performed with a PX2 thermal cycler (Thermo Electron Corporation, Waltham, MA, USA) by incubating at $25^{\circ} \mathrm{C}$ for $10 \mathrm{~min}, 37^{\circ} \mathrm{C}$ for $2 \mathrm{~h}$, and terminated by incubating at $85^{\circ} \mathrm{C}$ for $5 \mathrm{~s}$. Real-time PCR was performed on a PRISM 7900HT Sequence Detection System (Applied Biosystems) with SDS 2.3 software (Applied Biosystems) in 384-well plates using TaqMan gene expression Master Mix and assays including primers/probes (Applied Biosystems, listed in Table 1) using $10 \mathrm{ng}$ cDNA as template in each reaction.

\section{Data analysis}

GenomeStudio-exported files were imported into GeneSpring GX11.0 software (Agilent Technologies). Each experiment (7 and 30 days) was analyzed separately. Initially, probes were filtered using a $P$ value cutoff of $0 \cdot 85$ (versus background) to remove those probes for which no transcript was detected. Using the detection $P$ values initially generated in GenomeStudio, probes were required to have detectable signals in $100 \%$ of the samples in at least one group to be included in the subsequent statistical analysis. The goal of this filtering was to eliminate transcripts not reliably detected, while retaining genes that were efficiently expressed in only one group. Values were then normalized on a per gene basis to the $d w / d w+$ saline group. Differentially expressed genes were identified based on both statistical significance $(P<0 \cdot 05$, oneway ANOVA between the groups) and a filter of fold change (FC) $\geq 1 \cdot 2$ in accordance with standards for microarray

\section{Results} composition in GH-deficient dwarf animals

Consistent with previous data that $\mathrm{GH}$ administration promotes somatic growth and development, our results clearly indicated that peripheral GH increased body weight and lean mass. Compared with HZ animals with normal growth, dwarf animals with GHD exhibited dramatically reduced body weight, and peripheral GH replacement accelerated gains in body weight. After 7 and 30 days of injection, average body weight of GH-injected dwarf animals was $17 \cdot 6$ and $40 \cdot 0 \%$ higher than that of saline-treated dwarf rats respectively $(P<0.001$ for both comparisons, Fig. 1).

In addition to effects on body weight, 30 days $\mathrm{GH}$ replacement accelerated growth of lean mass. After injection, the $d w / d w+$ GH group exhibited $42.9 \%$ greater average lean mass compared with saline-treated dwarf rats $(P<0 \cdot 001$, $d w / d w+\mathrm{GH}$ versus $d w / d w+$ saline), and the rate of lean mass accumulation was also increased in response to GH treatment $(1 \cdot 79 \pm 0.03 \mathrm{~g} /$ day in $d w / d w+\mathrm{GH}$ versus

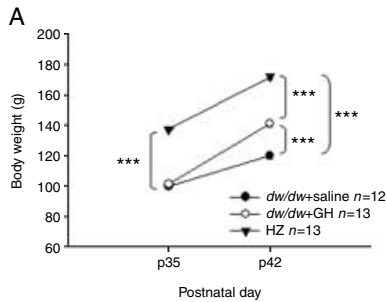

Figure 1 Peripheral replacement of $\mathrm{GH}$ to $d w / d w$ rats for 7 (A) or 30 days (B) accelerates the growth of total body weight in dwarf rats. Data represent mean \pm S.E.M. ${ }^{* * *} P<0.001$ in the indicated comparisons. $d w / d w+$ saline, $d w / d w$ rats injected with saline; $d w / d w+\mathrm{GH}, d w / d w$ rats injected with recombinant porcine $\mathrm{GH}$ (300 $\mu \mathrm{g}$, twice per day); HZ, heterozygotes injected with saline.
GH replacement increases body growth and modifies body

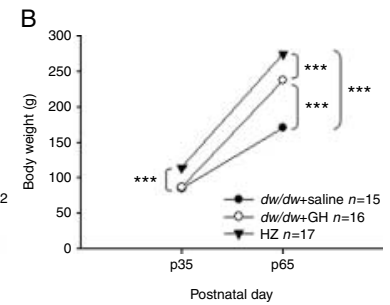



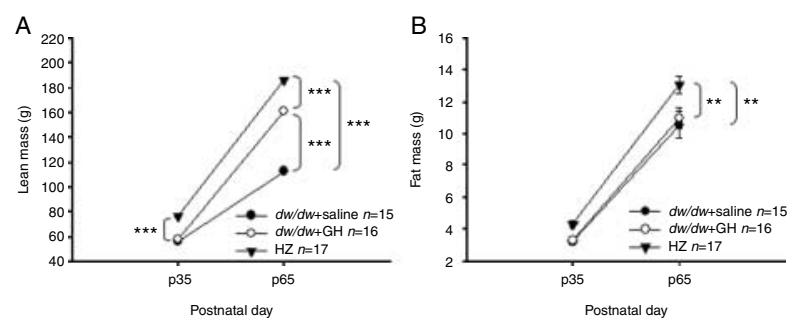

Figure 2 Peripheral $\mathrm{GH}$ replacement to $d w / d w$ rats for 30 days preferentially accelerates lean growth. (A) After 30 days $\mathrm{GH}$ replacement, the $d w / d w+\mathrm{GH}$ group exhibited higher lean mass $(P<0 \cdot 001)$ and achieved a greater rate of lean mass accumulation $(P<0.001)$ compared with the $d w / d w+$ saline group. (B) Fat mass was not different among the three groups on the day before the injection started but at the end of the study, the $d w / d w$ animals, injected with either $\mathrm{GH}$ or saline, demonstrated significantly less fat mass than the $\mathrm{HZ}$ group $(P<0 \cdot 01)$. However, the rate of fat mass growth did not differ among the three groups $(P=0 \cdot 363)$. Data represent mean \pm S.E.M. ${ }^{* *} P<0 \cdot 01$, and ${ }^{* * *} P<0 \cdot 001$ for the indicated comparisons.

$1 \cdot 02 \pm 0.03 \mathrm{~g} /$ day in $d w / d w+$ saline, $P<0 \cdot 001$, Fig. $2 \mathrm{~A})$. In contrast, the $d w / d w+\mathrm{GH}$ group exhibited similar fat mass compared with the $d w / d w+$ saline group, which was significantly lower than the $\mathrm{HZ}$ group $(P<0 \cdot 01)$, suggesting that peripheral $\mathrm{GH}$ replacement for 30 days during adolescence preferentially accelerated lean growth.

\section{GH increases serum IGF1 in dwarfs}

The effects of GH on serum IGF1 levels were confirmed by ELISA. At the end of either 7 or 30 days injection, serum IGF1 levels in the HZ group were significantly greater than the initial levels, confirming the peripubertal rise in IGF1 $(P<0.001$, Fig. 3). GHD during adolescence resulted in dramatically reduced serum IGF1 levels $(P<0.001$ each, $d w / d w+$ saline and $d w / d w+\mathrm{GH}$ versus $\mathrm{HZ}$ before injection). After $\mathrm{GH}$ replacement, the $d w / d w+\mathrm{GH}$ group exhibited significantly greater serum IGF1 levels than saline-treated dwarf littermates $(P<0.001 d w / d w+\mathrm{GH}$ versus $d w / d w+$ saline at both 7 and 30 days).

\section{IGF1 levels in the CSF are insensitive to GH replacement}

Compared with the HZ group, dwarf rats receiving saline exhibited significantly lower levels of IGF1 in CSF (46.99\% in the 7 -day study and $41.44 \%$ in the 30-day study, $P<0.001$ at both time points). After peripheral replacement of GH, IGF1 levels in the CSF remained relatively stable, with only a marginal increase occurring in the 30 days cohort $(P=0 \cdot 08$ $d w / d w+$ GH versus $d w / d w+$ saline, Fig. 4).

\section{GH replacement for 30 days increases IGF1 protein levels in the hippocampus}

Compared with the HZ group, saline-treated dwarf rats showed significantly lower IGF1 protein levels in the hippocampus $(P<0 \cdot 001 d w / d w+$ saline versus $\mathrm{HZ}$, at both
7 and 30 days). Peripheral GH replacement for 7 days did not increase hippocampal IGF1 levels (Fig. 5A), however, GH replacement for 30 days robustly restored hippocampal IGF1 levels that approached concentrations found in HZ animals $(P=0 \cdot 001, d w / d w+\mathrm{GH}$ versus $d w / d w+$ saline and $P=0 \cdot 52$, $d w / d w+\mathrm{GH}$ versus HZ, Fig. 5B).

A significant, positive correlation was observed between hippocampal IGF1 levels and serum IGF1 across all groups $\left(r^{2}=0.336, P<0 \cdot 001\right.$, Fig. 6$)$, indicating that the maintenance of local IGF1 levels in the hippocampus is dependent on circulating IGF1.

\section{GH replacement modifies gene expression in the hippocampus}

The results of the array analysis are available at the NIH GEO (Gene Expression Omnibus: http://www.ncbi.nlm.nih.gov/geo/ query/acc.cgi?token $=$ xbevncikqukiwfw\&acc $=$ GSE29512). Out of 22519 total probes on the Illumina Rat Array, 12077 probes in the 7-day study, and 12145 probes in the 30 -day study were confidently detected. Compared with the $d w / d w+$ saline group in the 7-day study, 81 probes, corresponding to 81 individual genes, showed differential expression in the $\mathrm{HZ}$ animals $(P<0.05$ and $\mathrm{FC} \geq 1 \cdot 2)$. Similarly, 39 genes (39 probes) were modified in response to GH replacement $(P<0 \cdot 05$ and $\mathrm{FC} \geq 1 \cdot 2)$, with 12 genes overlapping between the $\mathrm{HZ}$ and $d w / d w+\mathrm{GH}$ groups (Fig. 7A). In the 30-day study, 87 probes, corresponding to 87 individual genes were differentially expressed between $\mathrm{HZ}$ and saline-treated dwarf animals $(P<0.05$ and $\mathrm{FC} \geq 1.2)$ while 21 genes (21 probes) were modified by $\mathrm{GH}$ replacement $(P<0.05$ and $\mathrm{FC} \geq 1.2)$ with four genes overlapping (Fig. 7B). For all the overlapping genes, the trend of differential expression (up- or downregulation) was the same in $\mathrm{HZ}$ and $d w / d w+\mathrm{GH}$ groups compared with the $d w / d w+$ saline group. Hierarchically clustered heat maps were constructed and indicated that the gene expression pattern in the $d w / d w+\mathrm{GH}$ group approaches the $\mathrm{HZ}$ group in the
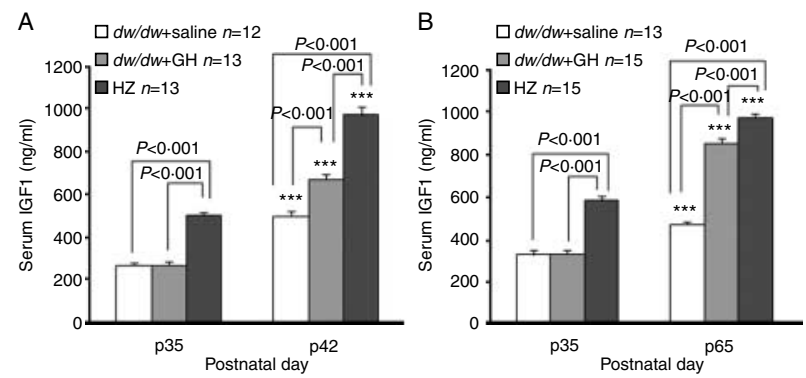

Figure 3 Peripheral GH replacement to $d w / d w$ rats for either 7 (A) or 30 days (B) increased serum levels of IGF1. Before injection, $d w / d w+$ saline and $d w / d w+\mathrm{GH}$ groups had similar serum IGF1 levels $(P=0.57$ in the 7-day study and $P=0.706$ in the 30-day study). After $\mathrm{GH}$ replacement, the $d w / d w+\mathrm{GH}$ group exhibited significantly greater serum IGF1 levels compared with $d w / d w+$ saline group $(P<0 \cdot 001$ in both the 7 - and 30-day studies). Data represent mean \pm S.E.M. ${ }^{* * *} P<0 \cdot 001$ within-group comparison, before and after injection. 
A

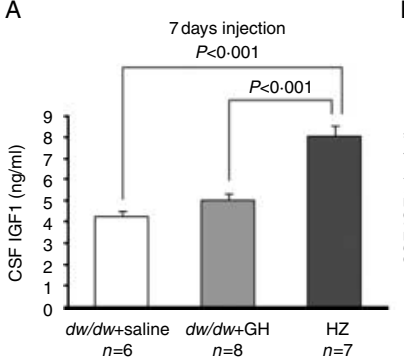

B

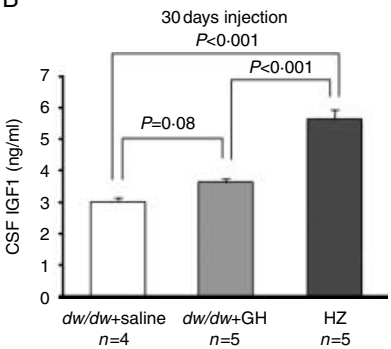

Figure 4 CSF IGF1 levels are insensitive to peripheral $\mathrm{GH}$ replacement. Saline-treated dwarf rats exhibited significantly reduced CSF IGF1 levels compared with $\mathrm{HZ}$ animals $(46.99 \%$ reduction in the 7 -day study (A) and $41.44 \%$ reduction in the 30-day study (B), $P<0 \cdot 001$ at both time points). Peripheral $\mathrm{GH}$ replacement failed to cause a significant change in CSF IGF1 ( $P=0.164$ in the 7 days study and $P=0.08$ in the 30 days study). Data represent mean \pm S.E.M.

7-day study (Fig. 7C) but is similar with the $d w / d w+$ saline group in the 30-day study after longer replacement (Fig. 7D), indicating transient changes in gene expression. These temporally specific alterations in gene expression may be an interaction between the effects of GH and developmentrelated changes, leading to alterations at the protein level and eventually modifications in cognition.

The list of differentially expressed genes $(P<0.05$ and FC $\geq 1 \cdot 2$, compared with the $d w / d w+$ saline group) were imported into Ingenuity Pathway Analysis software to analyze the interrelated genes. Compared with the $d w / d w+$ saline group, the most significantly regulated networks in the $\mathrm{HZ}$ and $d w / d w+\mathrm{GH}$ groups in the 7-day study were focused on cellular assembly and organization, cell signaling and cell interactions, cellular growth and proliferation, and cell morphology. Genes with differential expression in the $d w / d w+\mathrm{GH}$ group also mapped to networks including hematological system and nervous system development and function (Supplementary Table 1, see section on supplementary data given at the end of this article). In the 30-day study, the overlapping networks between $d w / d w+\mathrm{GH}$ and $\mathrm{HZ}$ groups were focused on cell death, cell signaling and interactions, immune response and nervous system development and function. Differentially regulated genes in the HZ group also mapped to networks involved in development and posttranslational modification (Supplementary Table 2, see section on supplementary data given at the end of this article).

Focused real-time PCR was performed to validate specific genes from the microarray results. Consistent with results from the microarray analysis, transcript levels of Igf1 and the $I g f 1 R$ were similar among the three groups after 7 or 30 days of treatment (Fig. 8). Differential expression of six transcripts was confirmed by PCR (Fig. 9): arachidonate 15-lipoxygenase (Alox15) was increased in the $d w / d w+\mathrm{GH}$ group in the 7 days study (Fig. 9A); Loc287167 (globin, $\alpha$ ), MGC727933 ( $\mathrm{Hb}, \beta$ adult major chain, also known as $H b b-b 1)$, and $\mathrm{Hb} \alpha$, adult chain $2(\mathrm{Hba-a2})$ were increased in the $d w / d w+\mathrm{GH}$ group in both the 7- and 30-day studies

compared with the $d w / d w+$ saline group; MGC72793 also showed increased levels in the HZ group in the 30-day study and $\mathrm{Hba-a2}$ was also increased in the HZ group at 7 days (Fig. 9B-D); calcium/calmodulin-dependent protein kinase kinase 2, $\beta$ (Camkk2) was increased in both the $\mathrm{HZ}$ and $d w /$ $d w+\mathrm{GH}$ groups in the 7-day study (Fig. 10A); and pleiotrophin (Ptn) was upregulated in the $d w / d w+\mathrm{GH}$ group in the 30-day study (Fig. 10B).

\section{Discussion}

Previous studies have provided compelling evidence that IGF1 is necessary for normal brain function (Aleman \& Torres-Aleman 2009). However, the source of IGF1 that is necessary to support brain function remains controversial. IGF1 gene and protein expression occurs in neurons and glia as well as vascular cells. In addition, circulating IGF1 has been found to cross the blood-brain barrier (Armstrong et al. 2000, Carro et al. 2000). Nevertheless, whether Igf1 gene expression in the brain can compensate for changes in the levels of circulating IGF1 or uptake of IGF1 through the blood-brain barrier remains unknown. In this study, we used GH-deficient dwarf animals to investigate the effects of circulating GH/IGF1 deficiency during adolescence, a period during which blood IGF1 levels are normally elevated, and investigated IGF1 gene and protein expression in brain tissue and IGF1 levels within the CSF. Our results demonstrate for the first time that the rise of circulating IGF1 during adolescence is necessary for the increase in IGF1 levels in the brain and that the absence of a rise in circulating IGF1 results in brain IGF1 deficiency. In contrast to previous reports that brain IGF1 in adults remained unaffected despite wide variations in circulating IGF1 levels (Adams et al. 2009), the strong, positive correlation between hippocampal and serum IGF1 in our results revealed a high dependence of brain IGF1 on the circulation during this critical time point of

A
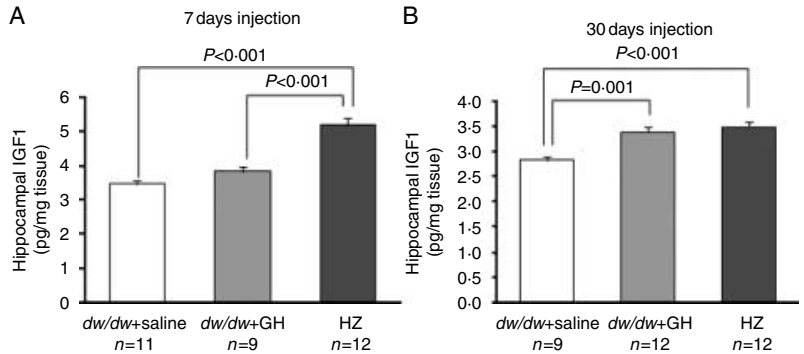

Figure 5 Peripheral $\mathrm{GH}$ replacement to $d w / d w$ rats for 30 days increased IGF1 levels in the hippocampus. (A) GH replacement for 7 days did not change IGF1 levels in the hippocampus $(P=0 \cdot 152$ $d w / d w+\mathrm{GH}$ versus $d w / d w+$ saline) but after 30 days replacement (B), the $d w / d w+\mathrm{GH}$ group had significantly greater IGF1 levels in the hippocampus ( $P=0.001 d w / d w+\mathrm{GH}$ versus $d w / d w+$ saline), which approached levels in the $\mathrm{HZ}$ group $(P=0.52 d w / d w+\mathrm{GH}$ versus HZ). Data represent the IGF1 concentration normalized by the weight of hippocampus and are shown as mean \pm s.E.M. 


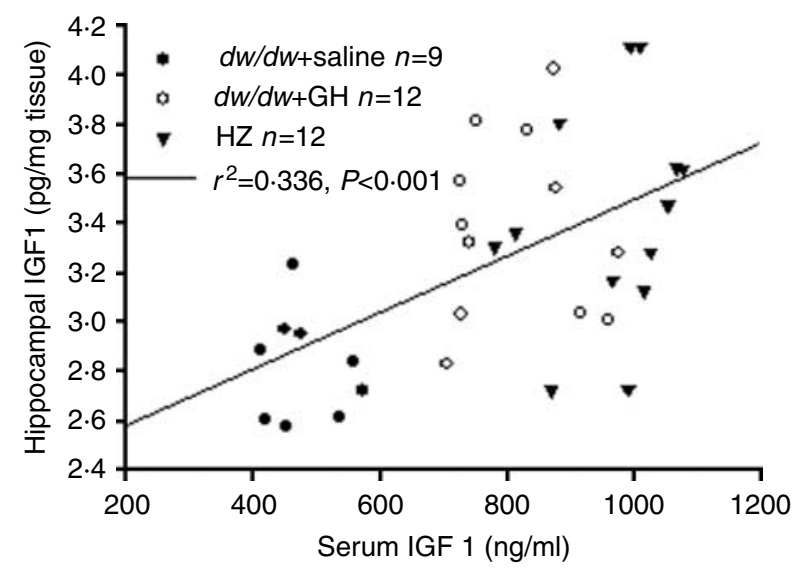

Figure 6 Hippocampal IGF1 protein levels exhibit a significant, positive correlation $\left(r^{2}=0 \cdot 336, P<0 \cdot 001\right)$ with serum IGF1 across the experimental cohort at p65.

development. The discrepancy between these studies may depend on the specific ages of the animals used in these experiments. Interestingly, our group has observed a similar dependence between serum and brain IGF1 levels in adult mice ( $~ 9$ months) after reduction in circulating IGF1 using a viral vector approach (Mitschelen et al. 2011). Furthermore, we find that increases in circulating GH/IGF1 are necessary for induction of genes involved in vascular development, brain development, and regulation of synaptic plasticity, providing additional evidence for the importance of the adolescent rise of circulating IGF1.

Microarray analysis revealed that during adolescence, circulating GH and IGF1 regulate a number of functionally diverse genes in the brain. In particular, the majority of the genes regulated by these hormones are involved in cellular growth and signaling as well as endocrine and nervous system development and function. These findings provide molecular evidence that GH and/or IGF1 are active participants in brain development/maturation during adolescence. Using focused quantitative PCR, we have confirmed two categories of genes with differential expression, i.e. genes that are involved in vascular regulation and genes that regulate cognitive function.

Numerous studies have implicated a relationship between IGF1 levels and the regulation of the cerebral vasculature. In both humans and rodents, microvascular density (Bell \& Ball 1981, Jucker et al. 1990) and regional cerebral blood flow (Melamed et al. 1980, Shaw et al. 1984, Goldman et al. 1987) decrease with age, which are reversed, at least in part, by GH replacement (Sonntag et al. 1997). In addition, IGF1 has been reported to enhance vascular structure and function in the brain. For example, systemic IGF1 injection increased cerebral vascular density in adult mice; brain vascular remodeling in response to physical exercise is abrogated in liver-IGF1 deleted mice, and brain injury-induced angiogenesis is blocked by injection of anti-IGF1 (Lopez-Lopez et al. 2004). Furthermore, decrements of cerebral blood flow in old rats are reported to correlate significantly with learning and memory impairments (Goldman et al. 1987, Mitschelen et al. 2009), suggesting that cerebral vascular status is an important contributor to brain function. Recently, GH/IGF1 deficiency in Lewis dwarf $(d w / d w)$ rats has been linked to high incidence of intracranial hemorrhage when the animals reached old age, and this pathology could be delayed by GH replacement during adolescence (Sonntag et al. 2005). The effects of IGF1 on the vasculature could be partially due to the ability of IGF1 to reduce oxidative stress and/or inflammation in the vascular endothelial cell (Csiszar et al. 2008) and smooth muscle cell (Higashi et al. 2010). In this study, we found numerous genes related to vascular function were increased by $\mathrm{GH}$ treatment. Four genes were confirmed by PCR (Alox15, Hba-a2, $\alpha$-, and $\beta$-globins) providing further evidence for the role of IGF1 in vascular regulation and maintenance. Alox15 (also known as 15-LOX) not only has both pro- and anti-inflammation actions on the
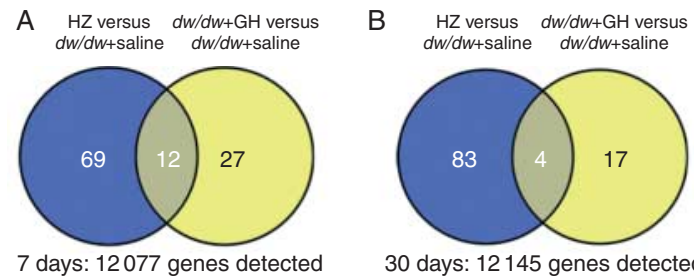

7 days: 12077 genes detected 30 days: 12145 genes detected
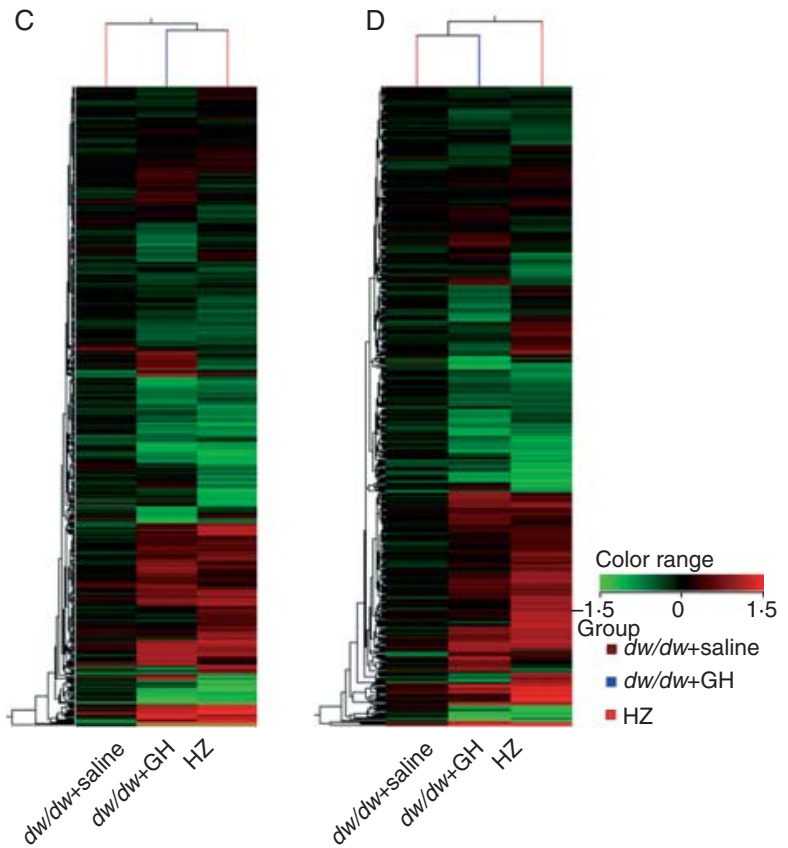

Figure 7 Analysis of gene expression data from the microarray assay. ( $A$ and $B$ ) Venn diagrams illustrate the number of genes with expression $>1 \cdot 2$-fold $(P<0 \cdot 05)$ in either the $d w / d w+$ saline or the $\mathrm{HZ}$ group compared with the expression levels in the $d w / d w+$ saline group. (C and D) Hierarchically clustered heat maps demonstrate similar differential gene expression between the $d w / d w+\mathrm{GH}$ and the $\mathrm{HZ}$ groups after 7 days $\mathrm{GH}$ treatment $(\mathrm{C})$, but after 30 days treatment, gene expression profiles are similar between the $d w / d w+\mathrm{GH}$ and the $d w / d w+$ saline groups (D). 

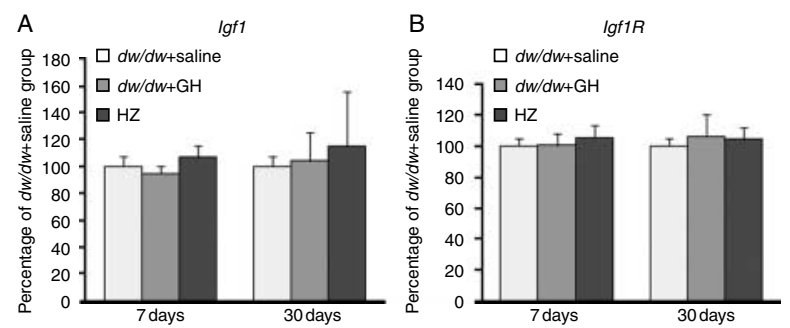

Figure 8 Gene expression of $\lg f 1$ (A) and its receptor (B) in the hippocampus were not different among the three groups at p42 or p65. Data are normalized to the mean value of the $d w / d w+$ saline group and represent mean \pm S.E.M. $n=4$ for each group.

vasculature (Wittwer \& Hersberger 2007), but also contributes to the production of vasodilator eicosanoids, and thus participates in the regulation of vascular tone, local blood flow, and blood pressure (Chawengsub et al. 2009). Unfortunately, there have been only limited studies on the roles of globin and $\mathrm{Hb}$ in the brain. Nevertheless, the results demonstrate that these genes are not restricted to the blood transport of oxygen and nutrient, but also are expressed in almost all oligodendrocytes as well as cortical and hippocampal astrocytes (Biagioli et al. 2009). Interestingly, mouse dopaminergic cell lines transfected with $\mathrm{Hb}$ demonstrate differential expression in genes involved in oxidative phosphorylation, indicating a relation between $\mathrm{Hb}$ and oxidative homeostasis (Biagioli et al. 2009). Previous studies using IGF1 replacement indicate that this hormone increases glucose metabolism and decreases oxidative stress in brain as well as vasculature. It is possible that these effects are mediated at least in part through the regulation of $\mathrm{Hb}$ and globins. However, further research will be necessary to support this conclusion. Thus, our findings of increased transcription of Alox 15, Hba-a2, $\alpha_{-}$, and $\beta$-globins in response to $\mathrm{GH}$ replacement provided further molecular evidence for the mechanism underlying the effect of IGF1 on the regulation of vascular structure and function. The effect of $\mathrm{GH}$ replacement on Alox15 and Hba-a2 gene expression appeared most pronounced after 7 days of treatment, potentially indicating a direct effect of $\mathrm{GH}$, whereas $\alpha$ - and $\beta$-globin gene expression demonstrated marked increases after 30 days of treatment, suggesting a complementary effect of increased IGF1 in the hippocampus. Nevertheless, further studies at the protein level will be required to explain the mechanism of the temporally specific regulation of these genes.

Age-related declines in circulating GH/IGF1 have been reported to be associated with impaired cognitive function (Rollero et al. 1998, Aleman et al. 1999). In aged animals, memory impairments are associated with decreased GH/IGF1 levels and can be attenuated by chronic administration of GHRH (Thornton et al. 2000), GH (Ramsey et al. 2004), or i.c.v. infusion of IGF1 (Markowska et al. 1998). Similarly, decreased serum IGF1 levels during adolescence result in cognitive deficits in mice (Trejo et al. 2007), and adolescent IGF1 deficiency in rats leads to impaired learning and memory in adulthood (Sonntag et al. 2005). The results of our microarray analysis revealed that IGF1 modifies a number of genes involved in CNS development as well as neurite growth and cell signaling. Focused qPCR confirmed two genes with increased transcription that are important for learning and memory. The Camkk2 gene encodes a kinase that belongs to the $\mathrm{Ca} /$ calmodulin-dependent protein kinase subfamily. This enzyme regulates calcium/calmodulindependent protein kinase 1 (Camk1) that induces the activation of extracellular signal-regulated kinase and neurite outgrowth in response to neuronal depolarization (Schmitt et al. 2004). In addition, Camkk2 regulates the recruitment of calcium-permeable AMPA receptors during synaptic potentiation (Guire et al. 2008). Previous studies using electrophysiological approaches have demonstrated that administering IGF1 induced an acute enhancement of AMPA receptor-mediated neurotransmission in the CA1 region of hippocampus through a postsynaptic mechanism (Ramsey et al. 2005). In addition, GH treatment of aged rats increased paired-pulse ratios in hippocampus by increasing $\mathrm{GABA}_{\mathrm{A}}$ receptors (Ramsey et al. 2004). Together with studies indicating that IGF1 restores the age-related decline of two subtypes (R2A and R2B) of NMDA receptors in rat hippocampus (Sonntag et al. 2000), the finding of increased Camkk2 transcription suggests an effect of GH/IGF1 on molecules involved in synaptic efficacy.

The relationship between IGF1, synaptic efficacy and neurite outgrowth has been previously reported. Both the numbers of synapses and synaptic architecture in the
$\mathrm{A}$

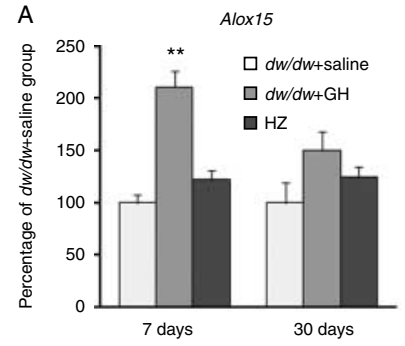

C MGC72793 ( $\beta$-globin)

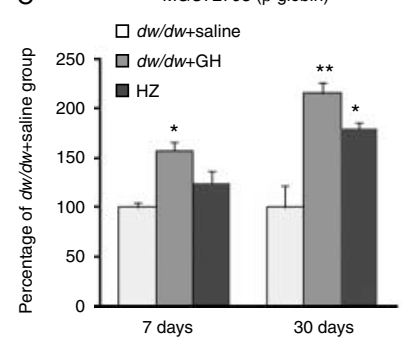

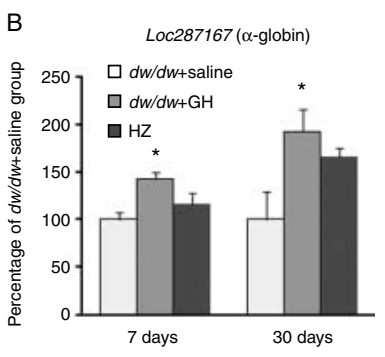

D

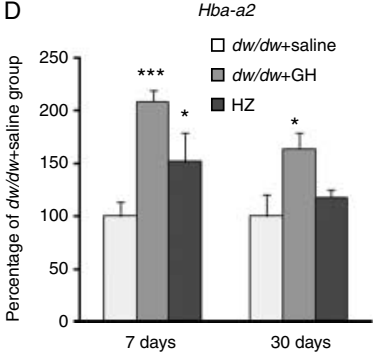

Figure 9 In both the 7- and 30-day studies, gene expression analysis by real-time PCR confirmed differential expression of genes in the hippocampus involved in vasculature. Genes included Alox15 (A), $\alpha$-globin (B), $\beta$-globin (C) and Hba-a2 (D). Data are normalized to mean values of the $d w / d w+$ saline group and represent mean \pm s.E.M. $n=4$ for each group. ${ }^{*} P<0 \cdot 05, * * P<0 \cdot 01$, and ${ }^{* * *} P<0 \cdot 001$ compared with the $d w / d w+$ saline group. 

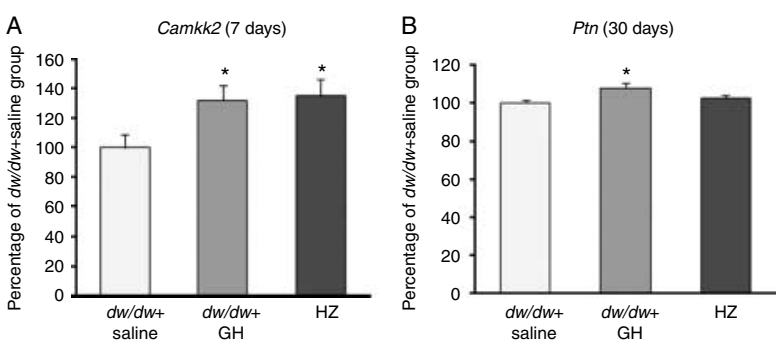

Figure 10 In both the 7- and 30-day studies, gene expression analysis by real-time PCR confirmed differential expression of genes in the hippocampus related to neuronal function, including Camkk2 (A) and Ptn (B). Data are normalized to mean values of the $d w / d w+$ saline group and represent mean \pm s.E.M. $n=4$ for each group. ${ }^{*} P<0 \cdot 05$ compared with the $d w / d w+$ saline group.

hippocampus decline with age (Shi et al. 2005), which is at least partially responsible for the impaired cognitive ability in aged animals. In contrast, i.c.v. infusion of IGF1 to old rats increased the length of the postsynaptic density and number of multiple spine boutons in CA1 area of hippocampus (Shi et al. 2005). In the $d w / d w+\mathrm{GH}$ group of our study, we found increased transcription of Ptn, a gene involved in brain development and function of the nervous system (Rauvala 1989, Li et al. 1990, Stoica et al. 2001). Alterations in this gene may be related to regulation of neurite outgrowth and upregulation of growth-associated protein43 mRNA (Yanagisawa et al. 2010). Therefore, our findings of increased Ptn gene expression in response to GH replacement support the role of IGF1 in enhanced synaptic plasticity that ultimately leads to increased cognitive function (Nieves-Martinez et al. 2010).

Interestingly, gene expression of Igf1 and its receptor in the hippocampus did not change in response to GHD or replacement and therefore it is unlikely that alterations in synthesis of these proteins contribute to the altered IGF1 protein levels in the brain. Hence, our data suggest that the reduction in hippocampal IGF1 in the $d w / d w+$ saline group and the restoration in the $d w / d w+\mathrm{GH}$ group are the result of uptake of IGF1 from the circulation rather than local/paracrine synthesis. This is supported by our observation of a positive correlation between hippocampal IGF1 and serum IGF1 levels. In contrast, hippocampal IGF1 levels demonstrate a weaker correlation with the CSF IGF1. Furthermore, the absence of restoration of IGF1 levels in the CSF by GH replacement for either 7 or 30 day GH treatment indicates that uptake of circulating IGF1 into the hippocampus is more likely through the brain vessel-parenchyma interface, than through the blood-CSF interface. Our findings are consistent with and complement the observation that neuronal activitystimulated uptake of circulating IGF1 into the brain was not through the CSF route (Nishijima et al. 2010). This result contradicts some previous reports in humans, in which GH treatment for a longer period was found to induce an increase in CSF IGF1 levels (Burman et al. 1995, Johansson et al. 1995). The discrepancy may be due to different durations of
GH replacement. Moreover, after GH replacement for 30 days, hippocampal IGF1 levels in the $d w / d w+$ GH group were almost completely restored while their CSF IGF1 levels were still remarkably lower than the HZ group. The temporally differential changes in hippocampal IGF1 and CSF IGF1 provide further evidence that the restoration of hippocampal IGF1 levels was not through a CSF route.

In summary, our study used a GH-deficient dwarf rat model to demonstrate that the rise in circulating IGF1 during adolescence is necessary to increase IGF1 levels in the brain. Our microarray analysis of gene expression in the hippocampus provides molecular support for the conclusion that IGF1 has important effects on the structure and function of vasculature as well as synaptic plasticity both of which are required for normal brain function.

\section{Supplementary data}

This is linked to the online version of the paper at http://dx.doi.org/10.1530/ JOE-11-0200.

\section{Declaration of interest}

The authors declare that there is no conflict of interest that could be perceived as prejudicing the impartiality of the research reported.

\section{Funding}

This work was supported by the NIH grants (P01 AG11370, NS 056218) and the Donald W Reynolds Foundation.

\section{References}

Adams MM, Elizabeth Forbes M, Constance Linville M, Riddle DR, Sonntag WE \& Brunso-Bechtold JK 2009 Stability of local brain levels of insulinlike growth factor-I in two well-characterized models of decreased plasma IGF-I. Growth Factors 27 181-188. (doi:10.1080/08977190902863639)

Aleman A \& Torres-Aleman I 2009 Circulating insulin-like growth factor I and cognitive function: neuromodulation throughout the lifespan. Progress in Neurobiology 89 256-265. (doi:10.1016/j.pneurobio.2009.07.008)

Aleman A, Verhaar HJ, De Haan EH, De Vries WR, Samson MM, Drent ML, Van der Veen EA \& Koppeschaar HP 1999 Insulin-like growth factor-I and cognitive function in healthy older men. Journal of Clinical Endocrinology and Metabolism 84 471-475. (doi:10.1210/jc.84.2.471)

Allison DB, Cui X, Page GP \& Sabripour M 2006 Microarray data analysis: from disarray to consolidation and consensus. Nature Reviews. Genetics 7 55-65. (doi:10.1038/nrg1749)

Armstrong CS, Wuarin L \& Ishii DN 2000 Uptake of circulating insulin-like growth factor-I into the cerebrospinal fluid of normal and diabetic rats and normalization of IGF-II mRNA content in diabetic rat brain. Journal of Neuroscience Research 59 649-660. (doi:10.1002/(SICI)1097-4547(20000301) 59:5 <649::AID-JNR8 $>$ 3.0.CO;2-W)

Arwert LI, Veltman DJ, Deijen JB, van Dam PS \& Drent ML 2006 Effects of growth hormone substitution therapy on cognitive functioning in growth hormone deficient patients: a functional MRI study. Neuroendocrinology 83 12-19. (doi:10.1159/000093337)

Bell MA \& Ball MJ 1981 Morphometric comparison of hippocampal microvasculature in ageing and demented people: diameters and densities. Acta Neuropathologica 53 299-318. (doi:10.1007/BF00690372) 
Biagioli M, Pinto M, Cesselli D, Zaninello M, Lazarevic D, Roncaglia P, Simone R, Vlachouli C, Plessy C, Bertin N et al. 2009 Unexpected expression of alpha- and beta-globin in mesencephalic dopaminergic neurons and glial cells. PNAS 106 15454-15459. (doi:10.1073/pnas. 0813216106)

de Bie HM, Oostrom KJ \& Delemarre-van de Waal HA 2010 Brain development, intelligence and cognitive outcome in children born small for gestational age. Hormone Research in Paediatrics 73 6-14. (doi:10.1159/ 000271911)

Bondy C, Werner H, Roberts CT Jr \& LeRoith D 1992 Cellular pattern of type-I insulin-like growth factor receptor gene expression during maturation of the rat brain: comparison with insulin-like growth factors I and II. Neuroscience 46 909-923. (doi:10.1016/0306-4522(92)90193-6)

Brucklacher RM, Patel KM, VanGuilder HD, Bixler GV, Barber AJ, Antonetti DA, Lin CM, LaNoue KF, Gardner TW, Bronson SK et al. 2008 Whole genome assessment of the retinal response to diabetes reveals a progressive neurovascular inflammatory response. BMC Medical Genomics 1 26. (doi:10. 1186/1755-8794-1-26)

Burman P \& Deijen JB 1998 Quality of life and cognitive function in patients with pituitary insufficiency. Psychotherapy and Psychosomatics 67 154-167. (doi:10.1159/000012276)

Burman P, Broman JE, Hetta J, Wiklund I, Erfurth EM, Hagg E \& Karlsson FA 1995 Quality of life in adults with growth hormone $(\mathrm{GH})$ deficiency: response to treatment with recombinant human $\mathrm{GH}$ in a placebo-controlled 21-month trial. Journal of Clinical Endocrinology and Metabolism 80 3585-3590. (doi:10.1210/jc.80.12.3585)

Carro E, Nunez A, Busiguina S \& Torres-Aleman I 2000 Circulating insulinlike growth factor I mediates effects of exercise on the brain. Journal of Neuroscience 20 2926-2933.

Carroll PV, Christ ER, Bengtsson BA, Carlsson L, Christiansen JS, Clemmons D, Hintz R, Ho K, Laron Z, Sizonenko P et al. 1998 Growth hormone deficiency in adulthood and the effects of growth hormone replacement: a review. Growth Hormone Research Society Scientific Committee. Journal of Clinical Endocrinology and Metabolism 83 382-395. (doi:10.1210/jc. 83.2.382)

Carter CS, Ramsey MM, Ingram RL, Cashion AB, Cefalu WT, Wang ZQ \& Sonntag WE 2002 Models of growth hormone and IGF-1 deficiency: applications to studies of aging processes and life-span determination. Journals of Gerontology. Series A, Biological Sciences and Medical Sciences $\mathbf{5 7}$ B177-B188. (doi:10.1093/gerona/57.5.B177)

Charlton HM, Clark RG, Robinson IC, Goff AE, Cox BS, Bugnon C \& Bloch BA 1988 Growth hormone-deficient dwarfism in the rat: a new mutation. Journal of Endocrinology 119 51-58. (doi:10.1677/joe.0.1190051)

Chawengsub Y, Gauthier KM \& Campbell WB 2009 Role of arachidonic acid lipoxygenase metabolites in the regulation of vascular tone. American Journal of Physiology. Heart and Circulatory Physiology 297 H495-H507. (doi:10.1152/ajpheart.00349.2009)

Csiszar A, Labinskyy N, Perez V, Recchia FA, Podlutsky A, Mukhopadhyay P, Losonczy G, Pacher P, Austad SN, Bartke A et al. 2008 Endothelial function and vascular oxidative stress in long-lived GH/IGF-deficient Ames dwarf mice. American Journal of Physiology. Heart and Circulatory Physiology 295 H1882-H1894. (doi:10.1152/ajpheart.412.2008)

van Dam PS, de Winter CF, de Vries R, van der Grond J, Drent ML, Lijffijt M, Kenemans JL, Aleman A, de Haan EH, Koppeschaar HPCINPJ et al. 2005 Childhood-onset growth hormone deficiency, cognitive function and brain $\mathrm{N}$-acetylaspartate. Psychoneuroendocrinology 30 357-363. (doi:10.1016/j.psyneuen.2004.10.002)

Deijen JB, de Boer H, Blok GJ \& van der Veen EA 1996 Cognitive impairments and mood disturbances in growth hormone deficient men. Psychoneuroendocrinology 21 313-322. (doi:10.1016/0306-4530(95) 00050-X)

Deijen JB, de Boer H \& van der Veen EA 1998 Cognitive changes during growth hormone replacement in adult men. Psychoneuroendocrinology 23 45-55. (doi:10.1016/S0306-4530(97)00092-9)

D'Ercole AJ, Stiles AD \& Underwood LE 1984 Tissue concentrations of somatomedin C: further evidence for multiple sites of synthesis and paracrine or autocrine mechanisms of action. PNAS 81 935-939. (doi:10.1073/pnas.81.3.935)
Donahue CP, Kosik KS \& Shors TJ 2006 Growth hormone is produced within the hippocampus where it responds to age, sex, and stress. PNAS 103 6031-6036. (doi:10.1073/pnas.0507776103)

Freeman WM, Bixler GV, Brucklacher RM, Walsh E, Kimball SR, Jefferson LS \& Bronson SK 2009 Transcriptomic comparison of the retina in two mouse models of diabetes. Journal of Ocular Biology, Diseases, and Informatics 2 202-213. (doi:10.1007/s12177-009-9045-3)

Goldman H, Berman RF, Gershon S, Murphy SL \& Altman HJ 1987 Correlation of behavioral and cerebrovascular functions in the aging rat. Neurobiology of Aging 8 409-416. (doi:10.1016/0197-4580(87)90035-2)

Golgeli A, Tanriverdi F, Suer C, Gokce C, Ozesmi C, Bayram F \& Kelestimur F 2004 Utility of P300 auditory event related potential latency in detecting cognitive dysfunction in growth hormone $(\mathrm{GH})$ deficient patients with Sheehan's syndrome and effects of GH replacement therapy. European Journal of Endocrinology/European Federation of Endocrine Societies 150 153-159. (doi:10.1530/eje.0.1500153)

Guire ES, Oh MC, Soderling TR \& Derkach VA 2008 Recruitment of calcium-permeable AMPA receptors during synaptic potentiation is regulated by CaM-kinase I. Journal of Neuroscience 28 6000-6009. (doi:10. 1523/JNEUROSCI.0384-08.2008)

Higashi Y, Sukhanov S, Anwar A, Shai SY \& Delafontaine P 2010 IGF-1, oxidative stress and atheroprotection. Trends in Endocrinology and Metabolism 21 245-254. (doi:10.1016/j.tem.2009.12.005)

Hokken-Koelega A, van Pareren Y \& Arends N 2005 Effects of growth hormone treatment on cognitive function and head circumference in children born small for gestational age. Hormone Research 64 (Supplement 3) 95-99. (doi:10.1159/000089324)

Johansson JO, Larson G, Andersson M, Elmgren A, Hynsjo L, Lindahl A, Lundberg PA, Isaksson OG, Lindstedt S \& Bengtsson BA 1995 Treatment of growth hormone-deficient adults with recombinant human growth hormone increases the concentration of growth hormone in the cerebrospinal fluid and affects neurotransmitters. Neuroendocrinology 61 57-66. (doi:10.1159/000126813)

Jucker M, Battig K \& Meier-Ruge W 1990 Effects of aging and vincamine derivatives on pericapillary microenvironment: stereological characterization of the cerebral capillary network. Neurobiology of Aging 11 39-46. (doi:10.1016/0197-4580(90)90060-D)

Koltowska-Haggstrom M, Mattsson AF, Monson JP, Kind P, Badia X, Casanueva FF, Busschbach J, Koppeschaar HP \& Johannsson G 2006 Does long-term GH replacement therapy in hypopituitary adults with GH deficiency normalise quality of life? European Journal of Endocrinology/European Federation of Endocrine Societies 155 109-119. (doi:10.1530/eje.1. 02176)

Krysiak R, Gdula-Dymek A, Bednarska-Czerwinska A \& Okopien B 2007 Growth hormone therapy in children and adults. Pharmacological Reports 59 500-516.

Li YS, Milner PG, Chauhan AK, Watson MA, Hoffman RM, Kodner CM, Milbrandt J \& Deuel TF 1990 Cloning and expression of a developmentally regulated protein that induces mitogenic and neurite outgrowth activity. Science 250 1690-1694. (doi:10.1126/science.2270483)

Lijffijt M, Van Dam PS, Kenemans JL, Koppeschaar HP, de Vries WR, Drent ML, Wittenberg A \& Kemner C 2003 Somatotropic-axis deficiency affects brain substrates of selective attention in childhood-onset growth hormone deficient patients. Neuroscience Letters 353 123-126. (doi:10.1016/j.neulet. 2003.09.028)

Lopez-Lopez C, LeRoith D \& Torres-Aleman I 2004 Insulin-like growth factor I is required for vessel remodeling in the adult brain. PNAS 101 9833-9838. (doi:10.1073/pnas.0400337101)

Markowska AL, Mooney M \& Sonntag WE 1998 Insulin-like growth factor-1 ameliorates age-related behavioral deficits. Neuroscience 87 559-569. (doi:10.1016/S0306-4522(98)00143-2)

Melamed E, Lavy S, Bentin S, Cooper G \& Rinot Y 1980 Reduction in regional cerebral blood flow during normal aging in man. Stroke; a Journal of Cerebral Circulation 11 31-35.

Mitschelen M, Garteiser P, Carnes BA, Farley JA, Doblas S, Demoe JH, Warrington JP, Yan H, Nicolle MM, Towner R et al. 2009 Basal and 
hypercapnia-altered cerebrovascular perfusion predict mild cognitive impairment in aging rodents. Neuroscience 164 918-928. (doi:10.1016/j. neuroscience.2009.08.070)

Mitschelen M, Yan H, Farley JA, Warrington JP, Han S, Herenu CB, Csiszar A, Ungvari Z, Bailey-Downs LC, Bass CE et al. 2011 Long-term deficiency of circulating and hippocampal insulin-like growth factor I induces depressive behavior in adult mice: a potential model of geriatric depression. Neuroscience 185 50-60. (doi:10.1016/j.neuroscience.2011.04.032)

Morselt AF, Cambier PH \& James J 1973 Electron-microscopical and microphotometric studies on the breakdown of erythrocytes by macrophages. Histochemie. Histochemistry. Histochimie 37 161-168. (doi:10.1007/ BF00305587)

Myers SE, Whitman BY, Carrel AL, Moerchen V, Bekx MT \& Allen DB 2007 Two years of growth hormone therapy in young children with Prader-Willi syndrome: physical and neurodevelopmental benefits. American Journal of Medical Genetics. Part A 143 443-448. (doi:10.1002/ajmg.a.31468)

Nieves-Martinez E, Sonntag WE, Wilson A, Donahue A, Molina DP, Brunso-Bechtold J \& Nicolle MM 2010 Early-onset GH deficiency results in spatial memory impairment in mid-life and is prevented by $\mathrm{GH}$ supplementation. Journal of Endocrinology 204 31-36. (doi:10.1677/JOE09-0323)

Nishijima T, Piriz J, Duflot S, Fernandez AM, Gaitan G, Gomez-Pinedo U, Verdugo JM, Leroy F, Soya H, Nunez A et al. 2010 Neuronal activity drives localized blood-brain-barrier transport of serum insulin-like growth factorI into the CNS. Neuron 67 834-846. (doi:10.1016/j.neuron.2010.08.007)

Nyberg F \& Burman P 1996 Growth hormone and its receptors in the central nervous system - location and functional significance. Hormone Research $\mathbf{4 5}$ 18-22. (doi:10.1159/000184753)

Oertel H, Schneider HJ, Stalla GK, Holsboer F \& Zihl J 2004 The effect of growth hormone substitution on cognitive performance in adult patients with hypopituitarism. Psychoneuroendocrinology 29 839-850. (doi:10.1016/ S0306-4530(03)00151-3)

Pan W \& Kastin K 2000 Interactions of IGF-1 with the blood-brain barrier in vivo and in situ. Neuroendocrinology 72 171-178. (doi:10.1159/000054584)

Ramsey MM, Weiner JL, Moore TP, Carter CS \& Sonntag WE 2004

Growth hormone treatment attenuates age-related changes in hippocampal short-term plasticity and spatial learning. Neuroscience 129 119-127. (doi:10. 1016/j.neuroscience.2004.08.001)

Ramsey MM, Adams MM, Ariwodola OJ, Sonntag WE \& Weiner JL 2005 Functional characterization of des-IGF-1 action at excitatory synapses in the CA1 region of rat hippocampus. Journal of Neurophysiology 94 247-254. (doi:10.1152/jn.00768.2004)

Rauvala H 1989 An 18-kd heparin-binding protein of developing brain that is distinct from fibroblast growth factors. EMBO Journal 8 2933-2941.

Rollero A, Murialdo G, Fonzi S, Garrone S, Gianelli MV, Gazzerro E, Barreca A \& Polleri A 1998 Relationship between cognitive function, growth hormone and insulin-like growth factor I plasma levels in aged subjects. Neuropsychobiology 38 73-79. (doi:10.1159/000026520)

Ross JL 2005 Effects of growth hormone on cognitive function. Hormone Research 64 (Supplement 3) 89-94. (doi:10.1159/000089323)

Sartorio A, Molinari E, Riva G, Conti A, Morabito F \& Faglia G 1995 Growth hormone treatment in adults with childhood onset growth hormone deficiency: effects on psychological capabilities. Hormone Research 44 6-11. (doi:10.1159/000184582)

Schmitt JM, Wayman GA, Nozaki N \& Soderling TR 2004 Calcium activation of ERK mediated by calmodulin kinase I. Journal of Biological Chemistry 279 24064-24072. (doi:10.1074/jbc.M401501200)
Shaw TG, Mortel KF, Meyer JS, Rogers RL, Hardenberg J \& Cutaia MM 1984 Cerebral blood flow changes in benign aging and cerebrovascular disease. Neurology 34 855-862.

Shi L, Linville MC, Tucker EW, Sonntag WE \& Brunso-Bechtold JK 2005 Differential effects of aging and insulin-like growth factor-1 on synapses in CA1 of rat hippocampus. Cerebral Cortex 15 571-577. (doi:10.1093/ cercor/bhh158)

Smith CP, Dunger DB, Williams AJ, Taylor AM, Perry LA, Gale EA, Preece MA \& Savage MO 1989 Relationship between insulin, insulin-like growth factor I, and dehydroepiandrosterone sulfate concentrations during childhood, puberty, and adult life. Journal of Clinical Endocrinology and Metabolism 68 932-937. (doi:10.1210/jcem-68-5-932)

Sonntag WE, Lynch CD, Cooney PT \& Hutchins PM 1997 Decreases in cerebral microvasculature with age are associated with the decline in growth hormone and insulin-like growth factor 1. Endocrinology 138 3515-3520. (doi:10.1210/en.138.8.3515)

Sonntag WE, Bennett SA, Khan AS, Thornton PL, Xu X, Ingram RL \& Brunso-Bechtold JK 2000 Age and insulin-like growth factor-1 modulate $\mathrm{N}$-methyl-D-aspartate receptor subtype expression in rats. Brain Research Bulletin 51 331-338. (doi:10.1016/S0361-9230(99)00259-2)

Sonntag WE, Carter CS, Ikeno Y, Ekenstedt K, Carlson CS, Loeser RF, Chakrabarty S, Lee S, Bennett C, Ingram R et al. 2005 Adult-onset growth hormone and insulin-like growth factor I deficiency reduces neoplastic disease, modifies age-related pathology, and increases life span. Endocrinology 146 2920-2932. (doi:10.1210/en.2005-0058)

Stoica GE, Kuo A, Aigner A, Sunitha I, Souttou B, Malerczyk C, Caughey DJ, Wen D, Karavanov A, Riegel AT et al. 2001 Identification of anaplastic lymphoma kinase as a receptor for the growth factor pleiotrophin. Journal of Biological Chemistry 276 16772-16779. (doi:10.1074/jbc.M010660200)

Svensson J, Diez M, Engel J, Wass C, Tivesten A, Jansson JO, Isaksson O, Archer T, Hokfelt T \& Ohlsson C 2006 Endocrine, liver-derived IGF-I is of importance for spatial learning and memory in old mice. Journal of Endocrinology 189 617-627. (doi:10.1677/joe.1.06631)

Thornton PL, Ingram RL \& Sonntag WE 2000 Chronic [D-Ala2]-growth hormone-releasing hormone administration attenuates age-related deficits in spatial memory. Journals of Gerontology. Series A, Biological Sciences and Medical Sciences 55 B106-B112. (doi:10.1093/gerona/55.2.B106)

Trejo J, Piriz J, Llorens-Martin MV, Fernandez AM, Bolos M, LeRoith D, Nunez A \& Torres-Aleman I 2007 Central actions of liver-derived insulinlike growth factor I underlying its pro-cognitive effects. Molecular Psychiatry 12 1118-1128. (doi:10.1038/sj.mp.4002076)

Waynforth HB \& Flecknell PA 1992 Experimental and Surgical Technique in the Rat., London: Academic press.

Wittwer J \& Hersberger M 2007 The two faces of the 15-lipoxygenase in atherosclerosis. Prostaglandins, Leukotrienes, and Essential Fatty Acids $\mathbf{7 7}$ 67-77. (doi:10.1016/j.plefa.2007.08.001)

Yanagisawa H, Komuta Y, Kawano H, Toyoda M \& Sango K 2010 Pleiotrophin induces neurite outgrowth and up-regulates growthassociated protein (GAP)- 43 mRNA through the ALK/GSK3beta/betacatenin signaling in developing mouse neurons. Neuroscience Research $\mathbf{6 6}$ 111-116. (doi:10.1016/j.neures.2009.10.002)

Received in final form 24 June 2011

Accepted 12 July 2011

Made available online as an Accepted Preprint 12 July 2011 